\section{Veins and Lymphatics is taking its first steps}

\author{
Stefano Ricci \\ Ambulatorio Flebologico "Ricci", Rome, \\ Italy
}

Veins represent an important field of medicine. They are frequently involved in several diseases with a very wide range of severity. At one end of the spectrum, we have thrombosis and post-thrombotic syndrome, while at the other we have telangectasias, and a vast number of other conditions lie between these two extremes. Varicose veins are not always severe, but they affect an enormous number of people, with a consequent social and economic burden to society. Lymphology is also an important subject. Lymphatics play a role in many human diseases but lymphedema is a sort of Cinderella disease, neglected by patients, doctors and health care administrators. The name itself shows how little we know; a description of the clinical manifestation has been transformed into the name of the disease. Lymphedema is usually considered to be an inevitable event, be it congenital or secondary. Its incidence is thought to be growing each year, especially in poorer countries and in the field of oncology. Lymphedema treatment is mostly unsatisfactory and costs are high, while patient adherence to treatment is low.

Few journals specialize in phlebology and not all of them have a worldwide distribution. Today, publication in print, although universally accepted, has many limitations compared to the global communication opportunities of the Internet, where the exchange of information is almost in real time. Other prestigious journals include phlebology as a niche subject and the importance of this must be recognized given the growing interest in veins. However, as this specialization becomes increasingly refined and socially important it demands a more independent voice. There are even fewer journals specializing in lymphology partly because of the problems already set out above but also not least because of the limited funds available. So I strongly believe that there is definitely space for not just one more journal, but for a forum in which we can develop our common scientific interests.

It may take some time before V\&L takes its proper place beside those more established and internationally recognized reference journals. However, we believe there is still space for a cultural initiative such as the launch of a new journal, while taking advantage of an extremely powerful technological tool, the Internet, and the attraction of a new format. Naturally, it is up to us to do our job properly with rigor and determination. But we also need to keep our eyes open for new ideas. Our Editorial Board is made up of many of the top phlebologists and lymphologists in the field, and they will supervise the project and guarantee the highest scientific standards.

We have chosen to free ourselves from the restraints of traditional publishing and have chosen an online open access only format, a format that in the scientific world offers many important advantages:

- peer review

- immediate publication

- free access

- worldwide distribution and availability

- the possibility of using color figures, videos, information linkage procedures.

We welcome original articles, editorials, reviews, short reports and case reports, as well as invited commentaries. Debate and discussion will be encouraged in a correspondence section. In fact, sometimes letters are better
Correspondence: Stefano Ricci, Ambulatorio Flebologico "Ricci", Corso Trieste, 123 - Roma, Italy.

E-mail: vandl@tiscali.it

This work is licensed under a Creative Commons Attribution 3.0 License (by-nc 3.0).

(C)Copyright S. Ricci, 2012

Licensee PAGEPress, Italy

Veins and Lymphatics 2012; 1:e1

doi:10.4081/vl.2012.e1

able to focus on conflicting aspects of a specific argument, especially when the Internet can offer a simple and rapid exchange of ideas.

However, open access has a cost. In fact, the advantage of complete and free availability of ideas and experiences is only sustainable through the authors' participation in covering the costs of processing and publishing their articles. We intend to try to overcome this problem with the help of sponsors willing to support this project.

We are optimistic that, once we have a sufficiently high number of articles being presented for publication, the journal can stand on its own feet. At present, we are driven forward by optimism, enthusiasm and confidence in the participation and contribution of our many friends and colleagues around the world. We firmly believe this is a golden opportunity to spread and share our experiences in the field of phlebolymphology through an open access journal. It will not be easy but we believe it is time to rise to the challenge!

We warmly invite you to submit one or more papers, taking also advantage of this unique opportunity to share rapidly your work worldwide and - last but not the least! - currently at no cost. 